Article

\title{
The RUNE Experiment-A Database of Remote-Sensing Observations of Near-Shore Winds
}

\author{
Rogier Floors *, Alfredo Peña, Guillaume Lea, NikolaVasiljević, Elliot Simon \\ and Michael Courtney
}

DTU Wind Energy, Technical University of Denmark, Risø Campus, Roskilde 4000, Denmark; aldi@dtu.dk (A.P.); gule@dtu.dk (G.L.); niva@dtu.dk (N.V.); ellsim@dtu.dk (E.S.); mike@dtu.dk (M.C.)

* Correspondence: rofl@dtu.dk; Tel.: +45-5180-1527

Academic Editors: Deepak R. Mishra, Xiaofeng Li and Prasad S. Thenkabail Received: 31 August 2016; Accepted: 19 October 2016; Published: 26 October 2016

\begin{abstract}
We present a comprehensive database of near-shore wind observations that were carried out during the experimental campaign of the RUNE project. RUNE aims at reducing the uncertainty of the near-shore wind resource estimates from model outputs by using lidar, ocean, and satellite observations. Here, we concentrate on describing the lidar measurements. The campaign was conducted from November 2015 to February 2016 on the west coast of Denmark and comprises measurements from eight lidars, an ocean buoy and three types of satellites. The wind speed was estimated based on measurements from a scanning lidar performing PPIs, two scanning lidars performing dual synchronized scans, and five vertical profiling lidars, of which one was operating offshore on a floating platform. The availability of measurements is highest for the profiling lidars, followed by the lidar performing PPIs, those performing the dual setup, and the lidar buoy. Analysis of the lidar measurements reveals good agreement between the estimated 10-min wind speeds, although the instruments used different scanning strategies and measured different volumes in the atmosphere. The campaign is characterized by strong westerlies with occasional storms.
\end{abstract}

Keywords: coastal; experiment; lidar; near-shore; offshore; wind resources

\section{Introduction}

Near-shore wind measurements (i.e., within $\approx 12 \mathrm{~km}$ from the coast) are both scarce and sparse, and are needed for a number of reasons. First, a number of coastal wind farms are being planned and erected and their design and financial viability highly depends on the accuracy of wind resource estimates. Second, models that estimate atmospheric and oceanic parameters (used in a number of disciplines including wind-power meteorology) become uncertain in coastal areas due to the complexities of the land-sea interactions, the validity of their parametrizations and numerical approximations, and local topographic features that are not adequately captured [1,2]. Evaluation of such models with high-quality observations is therefore needed.

For wind resource estimation near the coast, microscale models such as the one included in the Wind Atlas Analysis and Application Program (WAsP) are normally used [3], although mesoscale models are becoming increasingly popular [4-6]. One of the latter examples is the Weather Research and Forecasting (WRF) model, whose outputs can been 'downscaled' with a microscale model to provide detailed wind resource estimations [7]. This downscaling is a two-way process: first, the mesoscale model output is 'generalized' to remove the effects of mesoscale topographic features and second the generalized wind climate is downscaled adding the effects of microscale topographic features [7]. Near the coast, downscaling has not been thoroughly tested and the RUNE database represents a unique opportunity for model and model-chain evaluation. 
The uncertainty in wind resource estimations can be reduced significantly by using measurements at the site of interest. Traditionally, these are performed with cup anemometers on meteorological masts, but these are often expensive to install (particularly offshore) and have a long lead time. Profiling lidars, i.e., those vertically profiling the wind using velocity azimuth display (VAD) scanning, have been commercially available for several years [8] and are generally accepted as wind resource tools [9]. Recently, scanning lidars that are able to perform a number of scanning trajectories due to a steerable scanning head have also appeared on the market or have been developed by research institutes and can be of great advantage when performing wind resource estimation in complex areas [10] or areas with limited access.

One of these scanning lidars is the long-range WindScanner; it can be used to map the line-of-sight (LOS) wind velocities over a predetermined scanning pattern [11-13] and, by assuming certain flow properties in the scanned volume, the wind speed components can be estimated. Three spatially-separated WindScanners can be synchronized and the flow field estimated without making any assumptions, while with two WindScanners the horizontal wind vector can be estimated by assuming that the vertical component is zero. Finally, one WindScanner can be used to estimate the horizontal wind speed by scanning a certain azimuthal sector and assuming the wind direction in this sector is constant. Detailed information about the pointing accuracy and the measuring volume of the WindScanners is given in [11]. For RUNE, it is important to determine whether it is sufficient to use one or two WindScanners for coastal wind resource assessment. Recently, lidars mounted on buoys and floating lidars have become available. In RUNE, we use measurements from a lidar buoy to compare to those from onshore-located WindScanners that scanned the flow over water.

Here, we present the lidar systems, the locations and the topographic conditions of the RUNE coastal site (Section 2). Section 2.1 shows the timeline of the campaign and the details of the scanning patterns. Settings of the lidars are given in Section 3. In Section 4, we present the wind climate, how the filtering of the measurements affected the data availability and an inter-comparison of the wind speeds estimated from the lidars. Finally, we provide conclusions and an outlook in Section 5. Measurements from an ocean buoy (sea surface temperature, wave parameters and currents) and three types of satellites are also available for RUNE [14]; here, we concentrate on the presentation of the lidar measurements only.

\section{Site and Instruments}

The RUNE near-shore experiment was conducted at the western coast of Denmark, as illustrated in Figure 1, on an area of about $9 \mathrm{~km} \times 5 \mathrm{~km}$ in the Lemvig municipality. A closer view of the area with the positions used for the installation of the lidars is shown in Figure 2.

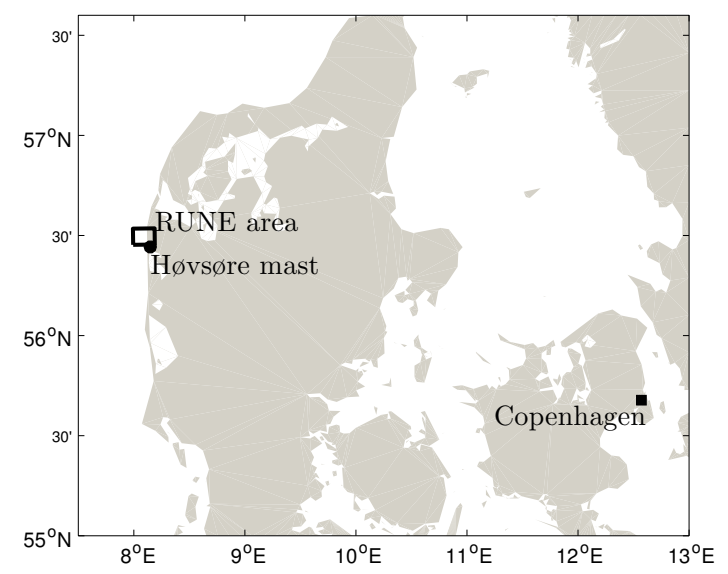

Figure 1. The RUNE experimental site in Denmark. The area of the coastal experiment is shown with the rectangle, and the positions of the meteorological mast at Høvsøre with the circle marker and Copenhagen with the square marker. 


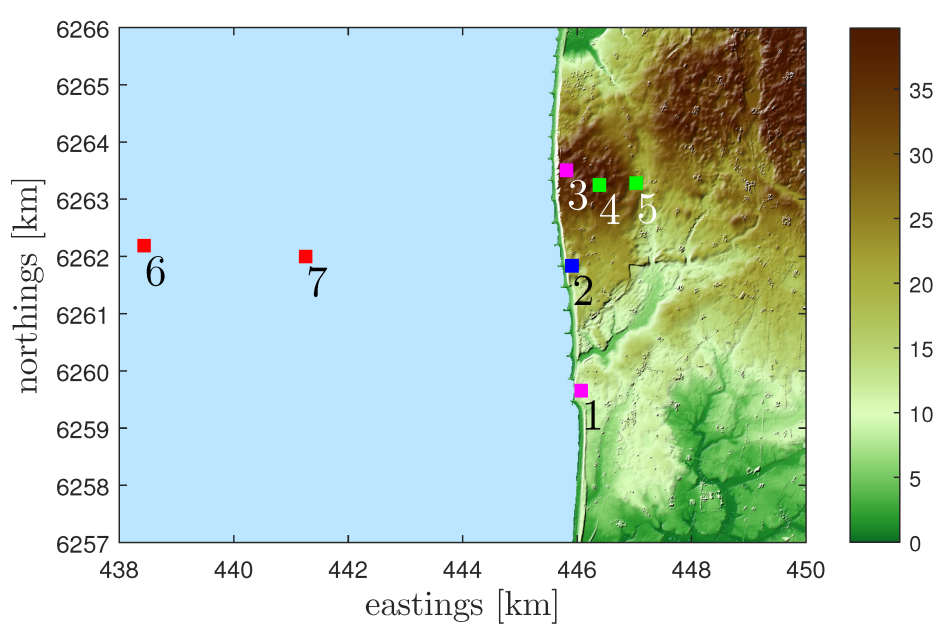

Figure 2. Topographic description of RUNE's coastal experimental area based on a digital surface model (UTM32 WGS84, Zone 32V). The positions of the lidars are shown with different markers (see Table 1 for details). The colorbar indicates the height ASL.

This area was selected because it is close to DTU's test station of wind turbines at Høvsøre (position 2 in Figure 2 is $6 \mathrm{~km}$ north from the test station's main building), where we routinely perform wind-power measurements including those from a meteorological mast [15]. It is also a typical location of interest for offshore wind development. The site is well-serviced by a $4 \mathrm{G}$ network useful for device monitoring and data retrieval and needed for synchronization of the WindScanners.

The Høvsøre area is a nearly flat coastal farmland. A sand embankment separates the North Sea from the grasslands. Moving northwards, the embankment transforms into dune cliffs covered by grass. Close to position 3 in Figure 2, the terrain is $\approx 43 \mathrm{~m}$ above sea level (ASL). This is an important feature as lidars need a clear LOS to measure wind velocities, and such topography aids in performing measurements over the North Sea with small elevation angles from onshore locations [16].

The lidars of the prototype WLS200S are longe-range WindScanners. For convenience, we have given our lidars names (Table 1), and these will be used throughout this paper. The number in brackets behind a name denotes the position. Lidar Vara (pos. 2) was deployed centrally along the coast near the cliff, on the grass next to a church, Koshava (pos. 1) to the south in open grassland in front of a house, and Sterenn (pos. 3) to the north at one of the highest points, $20 \mathrm{~m}$ south of a lighthouse. The long-range profiling lidar Alizé and the short-range profiling lidar WLS66 were installed next to Vara in pos. 2. Two other short-range profiling lidars, 3E and Bura, were installed inland at $\approx 250 \mathrm{~m}$ south, and $\approx 550$ and $\approx 1200 \mathrm{~m}$ west of Sterenn in pos. 4 and 5 , respectively. The location of the instruments was measured using a differential GPS system with an accuracy of $\approx 10 \mathrm{~cm}$. More information about the site identification for RUNE can be found in Courtney and Simon [16].

The topography of the area at a horizontal resolution of $1.6 \mathrm{~m}$ can be obtained via the website of the Danish Geodata Agency [17]. Land-cover data from the Corine dataset can be obtained via the website of the European Environmental Agency [18]. The land-use classes around the RUNE area are shown in Figure 3 and can be associated with an approximate surface roughness length $z_{0}$ for mesoscale applications by using Table 1 in [19]. There, the yellow area (non irrigated arable land) is associated with a $z_{0}$ value of $0.2 \mathrm{~m}$. For open farmland with very few buildings and trees, which is the type of land-cover at the site, the European Wind Atlas recommends a $z_{0}$ value of $0.03 \mathrm{~m}$ for microscale applications [20]. The differences between roughnesses for mesoscale and microscale applications are due to the applicability of the dataset; in mesoscale applications, the roughness has to be representative for a grid cell of a kilometre or more, which is often bigger than the local roughness due to the non-linear impact of obstacles on the flow. [15] found that the surface roughness at Høvsøre is lower than $0.03 \mathrm{~m}$ and that $z_{0}$ varies with season, direction, and atmospheric stability based on wind 
profile observations; the all-sector long-term $z_{0}$ is $0.012 \mathrm{~m}$. The villages of Bøvlingbjerg $(\approx 3 \mathrm{~km}$ east of the Høvsøre meteorological mast) and Ramme ( $\approx 5 \mathrm{~km}$ east of RUNE's experimental site) are the most prominent features that will impact the easterlies. The mixed forest area $\approx 10 \mathrm{~km}$ east of the site can also have an impact on the flow at high measuring heights during the campaign.

Table 1. Positions, coordinates (UTM WGS84, Zone 32V), types and main scanning strategies (usage) of the lidars during the RUNE campaign (see details in the text), including the information of the Høvsøre meteorological mast. The lidar buoy was used at two positions. The type is the commercial name given by the lidar manufacturer Leosphere (Orsay, France).

\begin{tabular}{ccccccc}
\hline Position & Name & Type & Usage & $\begin{array}{c}\text { Easting } \\
\mathbf{( m )}\end{array}$ & $\begin{array}{c}\text { Northing } \\
\mathbf{( m )}\end{array}$ & $\begin{array}{c}\text { Height } \\
\text { ASL (m) }\end{array}$ \\
\hline 1 & Koshava & WLS200S & Dual setup & $446,080.03$ & $6,259,660.30$ & 12.36 \\
2 & Vara & WLS200S & PPI & $445,915.64$ & $6,261,837.49$ & 26.38 \\
2 & Alizé & WLS70 & VAD & $445,915.64$ & $6,261,837.49$ & 26.38 \\
2 & WLS66 & WLS7v1 & VAD & $445,915.64$ & $6,261,837.49$ & 26.38 \\
3 & Sterenn & WLS200S & Dual setup & $445,823.66$ & $6,263,507.90$ & 42.97 \\
4 & 3E & WLS7v1 & VAD & $446,379.30$ & $6,263,251.46$ & 43.18 \\
5 & Bura & WLS7v1 & VAD & $447,040.74$ & $6,263,273.41$ & 24.93 \\
6 & Lidar buoy & WLS7v2 & VAD & 438,441 & $6,262,178$ & 0.00 \\
7 & Lidar buoy & WLS7v2 & VAD & 440,616 & $6,262,085$ & 0.00 \\
8 & Høvsøre mast & & Mast & 447,642 & $6,255,431$ & 0.32 \\
\hline
\end{tabular}

PPI = Plan Position Indicator, VAD = Velocity Azimuth Display.

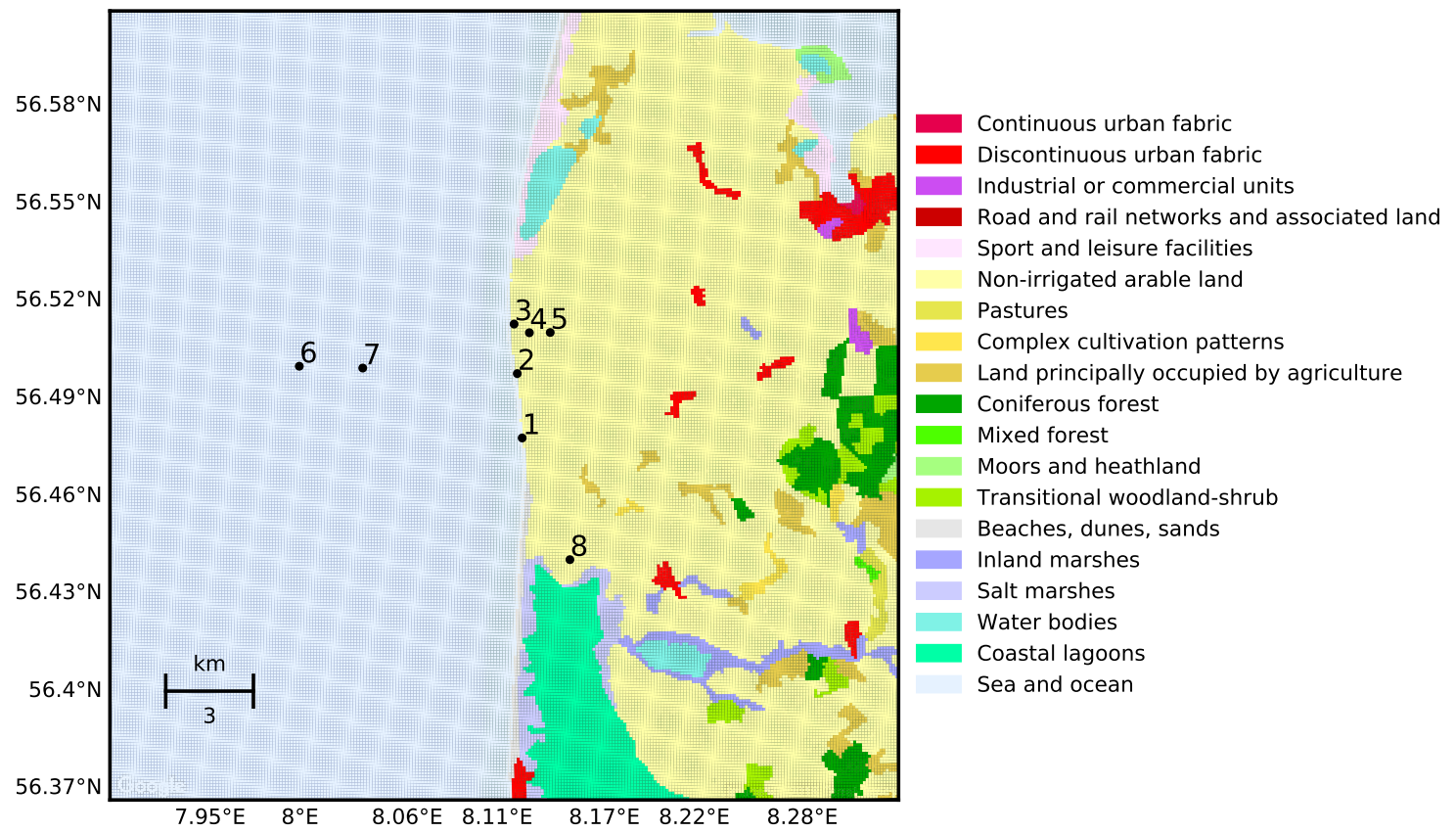

Figure 3. Land-use description of the terrain around the RUNE site. The main positions described in Section 3 are also given .

The stability conditions that occurred during the campaign were estimated using the observations from a sonic anemometer at the Høvsøre mast according to the Obukhov length $L$ at 10 -m height. The measurements from the sonic anemometers and stability conditions at Høvsøre are extensively discussed in [15,21]. Neutral $(|L| \geq 1000 \mathrm{~m})$, stable $(0 \mathrm{~m}<L<1000 \mathrm{~m})$ and unstable conditions $(-1000 \mathrm{~m}<L<0 \mathrm{~m})$ were occurring during $\approx 47 \%, 47 \%$ and $6 \%$ of the time, respectively. Unfortunately, the sonic anemometer mounted on the buoy was damaged after only two weeks of 
measurements and therefore the stability offshore could not be determined; it was likely predominantly unstable due to the influence of the warmer sea water. The impact of stability on the internal boundary layer is discussed in [21].

\subsection{Timeline of the Campaign}

The RUNE campaign started at the beginning of November 2015 and lasted until the end of February 2016. Four different phases were distinguished during the measurement campaign, based on the different scanning patterns in which the WindScanners were configured and described in Table 2. During phase 1, the lidars were calibrated using fixed targets and the scanning trajectories were prepared. During alignment and trajectory coding, all three WindScanners were used in a Plan Position Indicator (PPI) scenario at one elevation angle (see Section 3.1 for details). During this short phase, the area experienced several winter storm events.

Table 2. Description of the measurement phases during the RUNE campaign. At each phase, operational availability is defined as the hours of acquired data divided by the amount of hours that the system could have acquired data. PPI 1 or 3 refers to scans with one or three elevation angles. v1 and v2 refer to the dual setup with the a larger and shorter distance between range gates, respectively.

\begin{tabular}{ccccccc}
\hline Phase & System & $\begin{array}{c}\text { Start Time } \\
\text { Day/Month }\end{array}$ & $\begin{array}{c}\text { End Time } \\
\text { Day/Month }\end{array}$ & $\begin{array}{c}\text { Scenario } \\
\text { Type }\end{array}$ & $\begin{array}{c}\text { Data } \\
\text { (h) }\end{array}$ & $\begin{array}{c}\text { Operational } \\
\text { Availability (\%) }\end{array}$ \\
\hline \multirow{4}{*}{1} & Vara & $13 / 11$ & $26 / 11$ & PPI 1 & 251.5 & 79.25 \\
& Sterenn & $17 / 11$ & $27 / 11$ & PPI 1 & 215.8 & 92.83 \\
& Koshava & $17 / 11$ & $24 / 11$ & PPI 1 & 145.9 & 91.99 \\
\hline \multirow{4}{*}{2} & Vara & $26 / 11$ & $17 / 02$ & PPI 3 & 1575.2 & 79.38 \\
& Sterenn & $03 / 12$ & $25 / 12$ & dual v1 & 193.7 & 36.60 \\
& Koshava & $03 / 12$ & $25 / 12$ & dual v1 & 193.7 & 36.66 \\
\hline \multirow{2}{*}{3} & Sterenn & $25 / 12$ & $17 / 02$ & dual v2 & 1095.7 & 85.15 \\
& Koshava & $25 / 12$ & $17 / 02$ & dual v2 & 1056.7 & 82.12 \\
\hline \multirow{4}{*}{4} & Vara & $17 / 02$ & $29 / 02$ & PPI 1 & 269.7 & 91.91 \\
& Sterenn & $17 / 02$ & $29 / 02$ & RHI & 281.1 & 98.67 \\
& Koshava & $17 / 02$ & $29 / 02$ & RHI & 290.9 & 99.06 \\
\hline \multirow{4}{*}{ All } & Alizé & $09 / 11$ & $29 / 02$ & VAD & 2625 & 97.52 \\
& Bura & $12 / 11$ & $28 / 02$ & VAD & 2211 & 85.01 \\
& 3E & $01 / 11$ & $02 / 03$ & VAD & 2928.7 & 99.22 \\
& WLS66 & $01 / 11$ & $29 / 02$ & VAD & 2792.7 & 96.61 \\
& Lidar buoy 6 & $04 / 11$ & $07 / 12$ & VAD & 792 & 99.96 \\
& Lidar buoy 7 & $11 / 02$ & $30 / 03$ & VAD & 622.7 & 53.61 \\
\hline
\end{tabular}

PPI = Plan Position Indicator, VAD = Velocity Azimuth Display, RHI = Range Height Indicator.

Phase 2 started on November 26, when Vara (pos. 2) was setup in a PPI scenario at three elevation angles (Section 3.1), whereas Koshava (pos. 1) and Sterenn (pos. 3) follow trajectories in a synchronized manner, hereafter referred to as 'dual setup' (Section 3.2). During a repair following a major hardware failure experienced by Koshava, the dual-setup trajectories were modified to reduce the spatial distance between range gates. This period is referred to as phase 3. Due to the hardware failure, the operational availability of both Koshava and Sterenn is low (see Table 2).

During the final period, phase 4, Vara (pos. 2) was setup in a PPI scenario covering an azimuthal angle of $120^{\circ}$ at an elevation angle of $\approx 0^{\circ}$. The two other WindScanners were used in a range height indicator (RHI) mode and because their trajectories were configured so that they matched at a point $5 \mathrm{~km}$ west of position 2, the matching vertical positions can be used as a 'virtual' mast (Section 3.3). 


\section{Setup of the Lidars}

\subsection{PPI Scans}

During phase 1 , the three WindScanners performed PPIs covering an azimuthal range of $60^{\circ}$ with an elevation angle of $\approx 1^{\circ}$. The scans were centered at directions of $250^{\circ}, 270^{\circ}$ and $290^{\circ}$ for Sterenn (pos. 3), Vara (pos. 2) and Koshava (pos. 1), respectively. Each scan took 60 s to complete, i.e., the lidar was accumulating $1 \mathrm{~s}$ in each 1 degree azimuthal sector. There were 154 range gates for each LOS, except for Vara which had 156 range gates.

During phase 2 and 3 of the campaign, Vara (pos. 2) was the only lidar performing $60^{\circ}$ PPI scans facing west but at three different elevation angles. These elevation angles were chosen such that the scans reach 50, 100 and $150 \mathrm{~m}$ ASL near position 7. An integrated velocity azimuth processing (IVAP) algorithm was used to reconstruct the horizontal wind components at each range gate. The IVAP algorithm uses a summation of the angularly separated LOS velocities [22].

During phases 2 and 3, the full trajectory was taking $145 \mathrm{~s}$ to complete; $45 \mathrm{~s}$ for each scan at the three different elevations and $10 \mathrm{~s}$ to travel back to the first measurement point. Each scan obtained 45 LOS velocities with $1 \mathrm{~s}$ accumulation time. Each LOS contained 156 range gates from 100 to $8150 \mathrm{~m}$, so for each full scan 468 reconstructed horizontal wind components were obtained

During phase 4, Vara (pos. 2) was performing a PPI scan with an azimuthal range of $120^{\circ}$ centered at $270^{\circ}$. For each $1^{\circ}$, the lidar was accumulating LOS spectra during $1 \mathrm{~s}$. The elevation angle during this period was $\approx 0^{\circ}$ and for each LOS there were 159 range gates.

The reconstruction algorithm described in Simon and Courtney [23] was applied to the PPI scans in phases 2 and 3 only (so hereafter PPI refers to such PPIs) for each scan and data were filtered out if the average carrier-to-noise ratio (CNR) of the 45 LOSs at each range gate was below $-27 \mathrm{~dB}$. The estimated wind components were then averaged over 10, 30 and 60-min periods, i.e., using 4, 12 and 24 reconstructed velocities per averaged value, respectively. In this article, we only use the 10 min mean values.

\subsection{Dual Setup}

Koshava (pos. 1) and Sterenn (pos. 3) were configured to match their scans along three horizontal virtual lines at 50, 100 and $150 \mathrm{~m}$ ASL from $5 \mathrm{~km}$ west to $4 \mathrm{~km}$ east (inland) of position 2 (Figure 4). They acquired 45 LOSs per virtual line in $45 \mathrm{~s}$, corresponding to horizontal distances of $\approx 200 \mathrm{~m}$ between points. Like the PPI scenario in phases 2 and 3, the total scanning time amounted to $145 \mathrm{~s}$, including the $10 \mathrm{~s}$ that the scanner heads need to get back to their starting positions. LOS velocities were retrieved separately for each point and lidar and, from these, the horizontal wind speed components were reconstructed over a given period. To ensure the spatial proximity of two opposite range gates for the dual-setup reconstruction, 89 and 91 range gates were acquired per LOS and per system for phases 2 and 3, respectively.

In order to include all acceptable range-gate combinations, a collocating algorithm filtered out data that did not fulfil a certain distance threshold, resulting in the black points depicted in Figure 4. During phase 2, the range-gate positions were not well collocated in the $x$-direction (i.e., west-east), and therefore, the threshold in the $x$-direction was set to $51 \mathrm{~m}$. For the $y$ (north-south) and $z$ (vertical) directions and during phase 3 , the threshold was $10 \mathrm{~m}$. The reconstruction algorithm was applied to the 10, 30 and 60-min averaged LOS velocities of both systems, after filtering out data that did not fulfil the CNR threshold $(-26.5 \mathrm{~dB})$. Reconstructed points situated near the coast using the dual setup cannot be well established. This is due to errors introduced by the very small beam crossing angles. Work is ongoing to quantify the uncertainty of the flow in this area and therefore we do not use the dual-setup measurements near the coast in this article. 


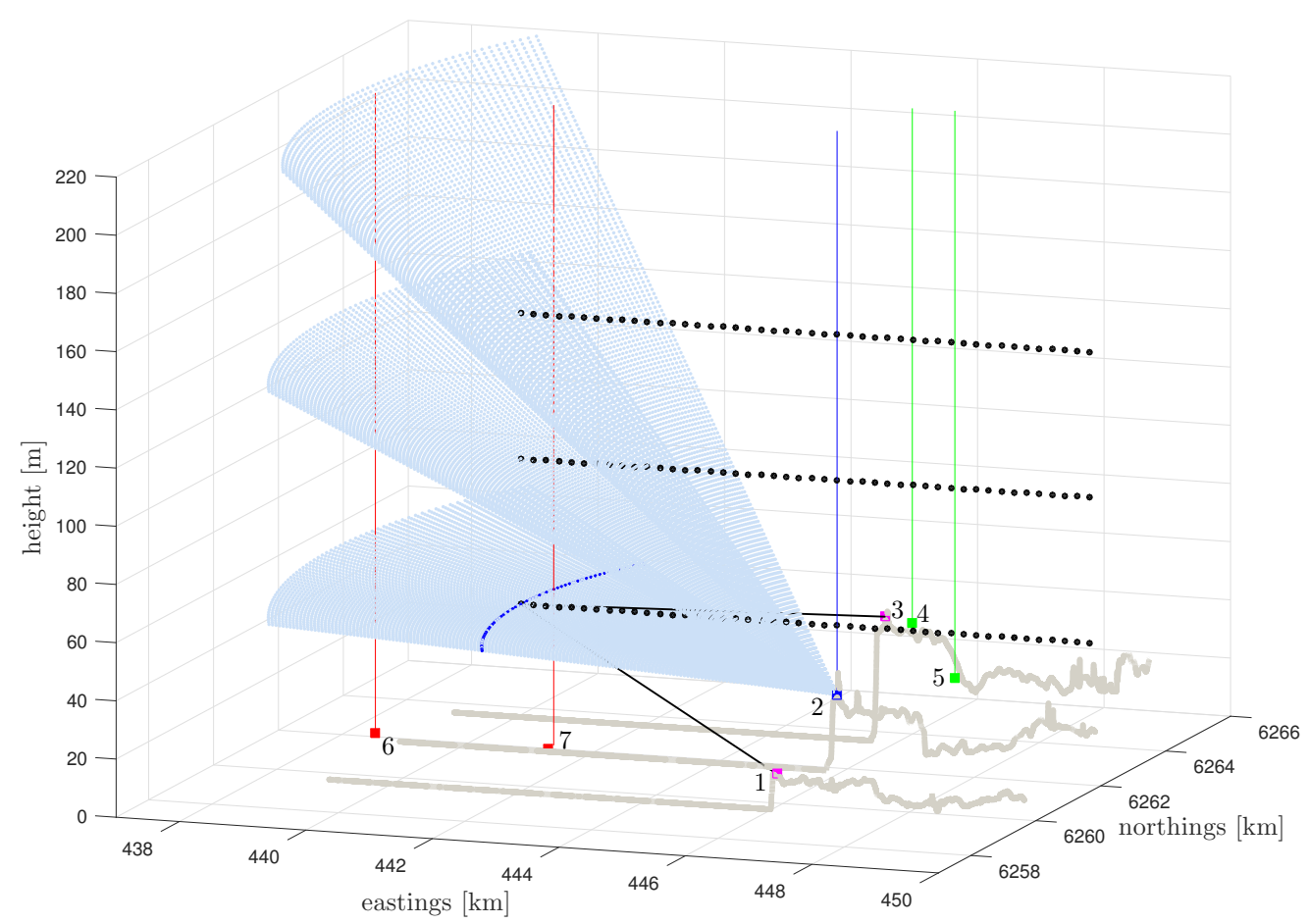

Figure 4. Overview of the scanning strategies during phases 2 and 3. Collocated points from the dual setup are shown in black circles and the two black lines show two laser beams focusing in position 7 . The points from the PPI scans are denoted with light blue points and dark blue points denote the first $60^{\circ}$ scan that is collocated with the first dual setup point at $50 \mathrm{~m}$ ASL. The vertical coloured lines denote the positions of the profiling lidars and the grey lines denote the terrain height at the northing locations of positions 1-3.

\subsection{Virtual Mast}

During phase 4, Koshava (pos. 1) and Sterenn (pos. 3) performed RHI scans that intersected at position 7. A vertical profile with range gates at 36 different heights can be obtained (see Table 3 ). For each 10 min interval, each height was sampled 16 times with $1 \mathrm{~s}$ accumulation time. Sterenn and Koshava had an azimuthal angle of $251^{\circ}$ and $293^{\circ}$ and $143^{\circ}$ and $144^{\circ}$ ranges gates, respectively. They both swept an elevation range from $\approx-0.5^{\circ}$ to $9.5^{\circ}$. The same reconstruction algorithm and CNR limit as those used for the dual setup were applied.

\subsection{VAD Scans}

The vertical profiling lidars performed VAD scans. Alizé (pos. 2) was configured to measure at 20 heights between 100 and $1500 \mathrm{~m}$ above lidar level (ALL). WLS66 (pos. 2) started to measure at $40 \mathrm{~m}$ ALL, and it was configured such that some of the range gates coincided with the dual-setup heights. With a terrain height of $26 \mathrm{~m}$, the range gates at 74 and $124 \mathrm{~m}$ ALL are close to the heights 100 and $150 \mathrm{~m}$ ASL. The same idea was used for the range gates at 57 and $107 \mathrm{~m}$ ALL for 3E (pos. 4), and 75 and $125 \mathrm{~m}$ ALL for Bura (pos. 5). Bura measured at more range gates than usual in a WindCube WLS7v1 (Leosphere, Orsay, France), because it was using modified software (WindSoft LR). All range gates of the VAD lidars are given in Table 3.

The sampling time per LOS was $\approx 3.5,1,1,5$, and 1 s for Bura, 3E, WLS66, Alizé and the lidar buoy, respectively. All lidars were sampling in 4 positions around the zenith, with a $90^{\circ}$ azimuthal separation between each other. The zenith angle was $30^{\circ}$ for the short-range lidars and $15^{\circ}$ for the long-range lidar (Alizé). The CNR threshold for the VAD lidars was set to $-22 \mathrm{~dB}$, except for Alizé which used a threshold of $-27 \mathrm{~dB}$. All samples within a $10 \mathrm{~min}$ period at all heights up to $130 \mathrm{~m}$ had to fulfill this threshold. 
Table 3. The heights of the range gates of the VAD lidars and those of the virtual mast scenario.

\begin{tabular}{cl}
\hline Name & Range Gate Height ALL (m) \\
\hline Alizé & $100,150,175,200,250,300,350,400,450$, every 100 m from 500-1500 \\
Bura & $30,35,40,50,62,75,87,100,112,125,140,155,175,200,250,300$ \\
3E & $40,57,70,88,107,125,150,200,250,300$ \\
WLS66 & $40,50,60,74,80,90,100,110,124,150$ \\
Lidar buoy & $40,47,59,79,97,117,134,147,172,197,209,247$ \\
\hline Name & Range Gate Height ASL (m) \\
\hline \multirow{3}{*}{ Virtual mast } & $5,28,52,75,99,122,146,169,192,217,275,298,322,345,368,392$, \\
& $757,793,461,486,520,544,568,591,615,639,662,687,710,734$, \\
\hline VAD = Velocity Azimuth Display, ASL = Above Sea Level, ALL = Above Lidar Level.
\end{tabular}

The lidar buoy was installed on November 4 . The floating lidar was installed as far offshore as possible, but still within the maximum range of the sector-scan setup (pos. 6). This location was chosen because the RUNE project aimed to evaluate mesoscale models and their grid spacing is usually in the order of kilometers. On 15 November, after a storm, it was found that the blades of the wind-power buoy generators were damaged and the buoy's motion sensor was not working properly. During another storm, the blades were again damaged and the lidar did not have electricity after 7 December. Due to the harsh weather conditions, it was only possible to relocate the buoy to a location (pos. 7) with less-frequent breaking waves by 11 February. There, the lidar buoy measured successfully until 30 March. Detailed documentation about the lidar buoy can be found in [24].

\section{Results}

\subsection{Wind Climate}

The RUNE campaign was characterized by periods of very windy weather with sustained winds from the west. Figure 5a panel shows the wind speeds from the cup anemometer at $100 \mathrm{~m}$ AGL at the Høvsøre meteorological mast (pos. 8). The wind speed at $100 \mathrm{~m}$ reaches more than $25 \mathrm{~m} \cdot \mathrm{s}^{-1}$ several times, with a maximum wind speed of $35.3 \mathrm{~m} \cdot \mathrm{s}^{-1}$ at 18:30:00 UTC on 29 November. The wind direction (Figure $5 \mathrm{~b}$ panel) is taken from measurements of a wind vane at $100 \mathrm{~m}$ AGL at the Høvsøre meteorological mast. These records show that the flow was characterized by westerlies during November and December and then a period of several weeks with mostly easterlies followed. After this intermezzo, westerlies were again predominant.

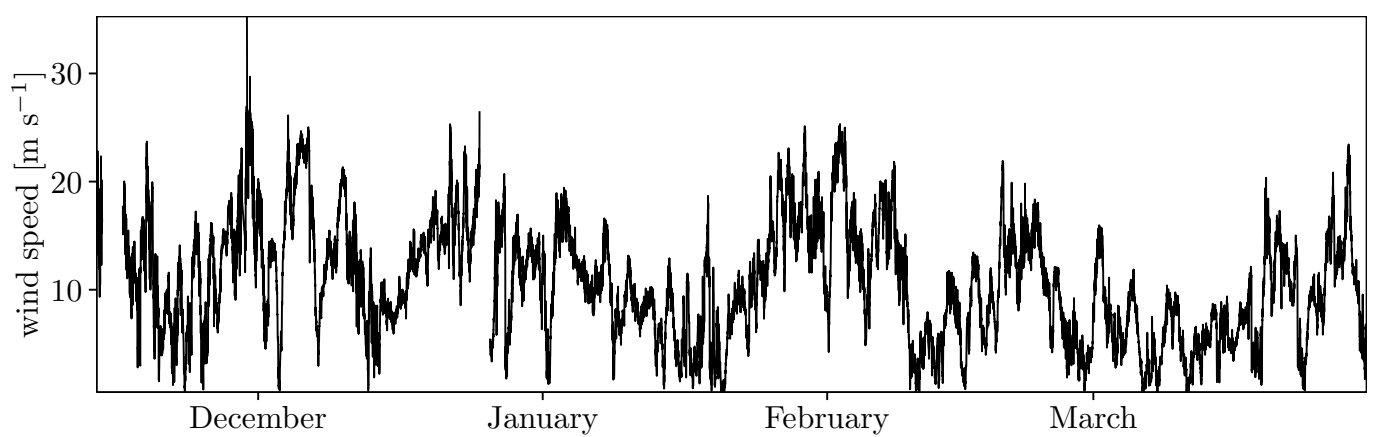

(a)

Figure 5. Cont. 


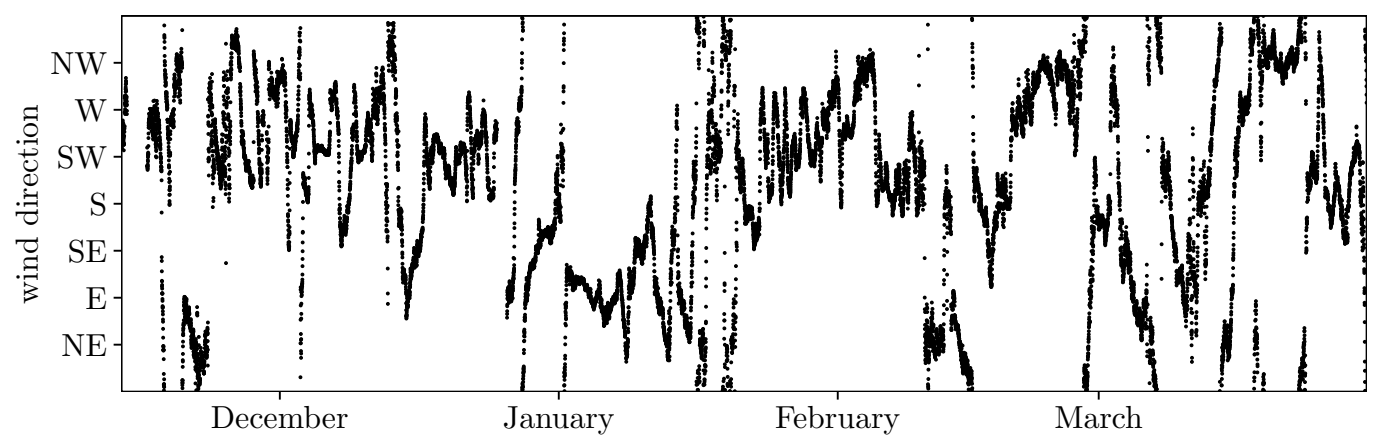

(b)

Figure 5. The wind speed (a) and the wind direction (b) at $100 \mathrm{~m}$ from $\mathrm{m}$ easurements of the Høvsøre meteorological mast during RUNE.

\subsection{Actual Availability}

The availability of measurements depends on the ability of the lidar to measure an accurate LOS velocity, which is mostly a function of the laser power and the presence of aerosols. We define 'actual availability' when all samples within a 10 min interval fulfilled the thresholds discussed in Section 3 and a reconstruction of the wind vector could be obtained. Figure 6 shows the actual availability of all lidars performing VAD, dual setup and RHI scans. It should be noted that only the PPI scans during phase 2 and 3 have been used to obtain reconstructed wind speeds.

For the PPI scans during phases 2 and 3, and for the dual setup during phases $2-4$, all data where a range at any distance fulfilled the CNR criteria have been marked as available; data where all range gates fulfil that criteria are more rare. The lidar buoy was not available for a large portion of the experiment, but measured also during March. The other lidars only measured until February.

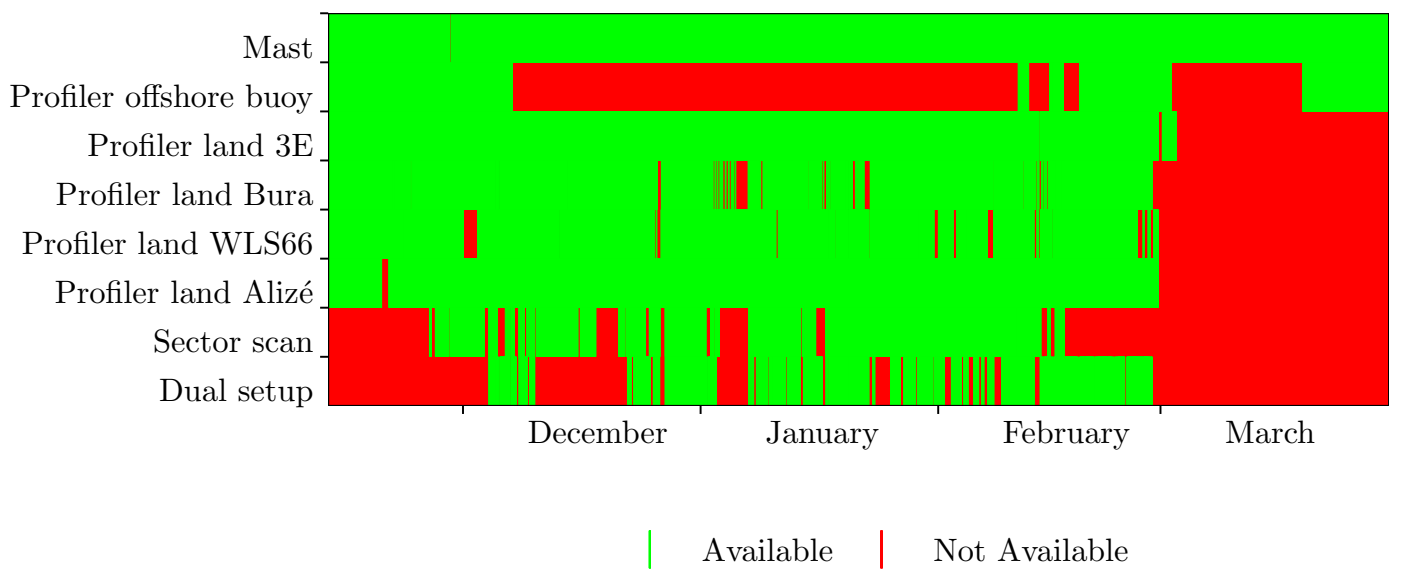

Figure 6. Actual availability of all reconstructed wind speeds in $10 \mathrm{~min}$ intervals that fulfilled the filtering criteria

Figure 7 shows the actual availability of the reconstructed horizontal wind speed components from the PPI and dual setup scans during phases 2 and 3 as a function of distance by assuming an operational availability of $100 \%$. The actual availability decreases with distance (west-east) from the devices. The highest scanned points in the vertical coordinate, level 3, generally have the lowest availability. Furthermore, availability from the dual setup is slightly lower than that of the PPI scan because Koshava (pos. 1) and Sterenn (pos. 3) were located further away from the positions where the wind components are reconstructed compared to Vara (pos. 2). The points over land with low availability are due to the laser beam hitting objects. 


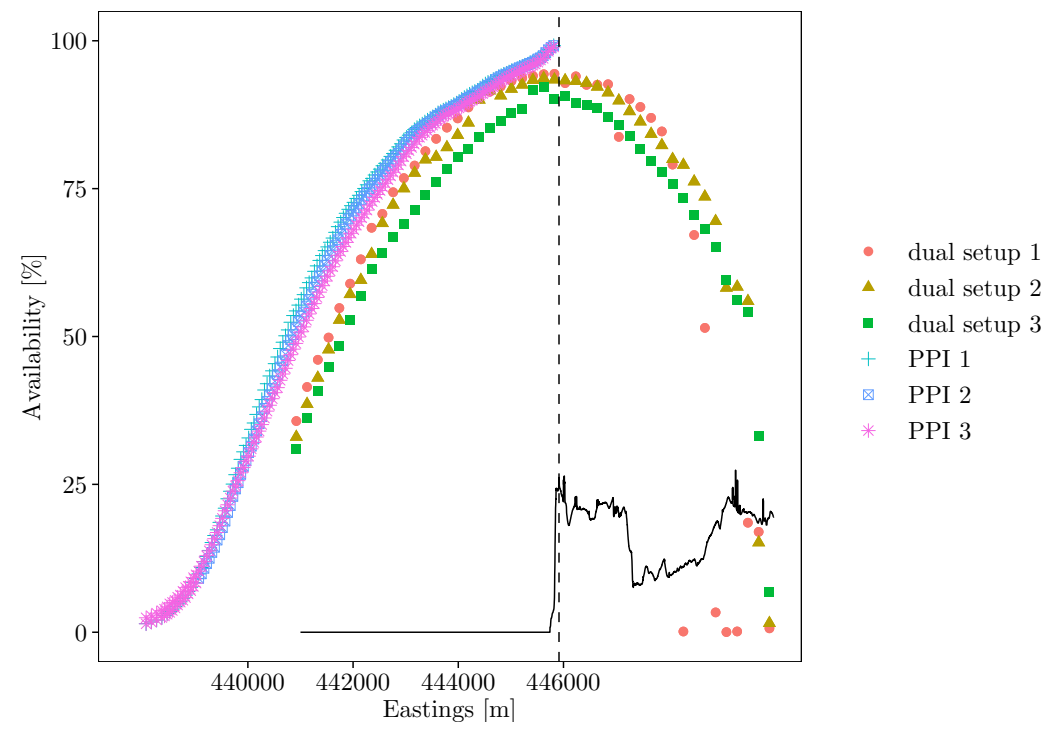

Figure 7. Actual availability of reconstructed wind speed components as a function of eastward position. The numbers 1, 2, and 3 refer to the vertical level of measurements of the PPI and dual setups. The dashed line indicates position 2 and the solid line is the height of the terrain (not to scale).

\subsection{Preliminary Intercomparisons}

\subsubsection{VAD Lidars}

In this section, we use a data set that is the result of merging all lidars in VAD mode that fulfill the filtering criteria. Despite the CNR filtering, some data were found, where Bura measured near-zero wind speeds and 3E measured realistic values of more than $5 \mathrm{~m} \cdot \mathrm{s}^{-1}$. These outliers were found within periods of near-zero temperatures (a comparison of Bura $10 \mathrm{~min}$ wind speeds with those from the Høvsøre meteorological mast at a similar level also showed these data). Therefore, 10 min intervals with an absolute difference of more than $5 \mathrm{~m} \cdot \mathrm{s}^{-1}$ between the wind from Bura and 3E at $150 \mathrm{~m}$ were excluded. The result is a data set with 464010 min means.

Figure 8a panel shows a scatter plot of the 126-m ASL 10 min mean wind speeds estimated from the collocated vertical profiling lidars WLS66 and Alizé in position 2, in order to get an idea of the quality of the data. The agreement is generally good (Pearson's linear correlation coefficient $R^{2}$ is 1.00). Alizé generally measures slightly higher wind speeds than WLS66 $(\approx 3 \%)$. The mechanism responsible for this is yet unknown but it might be due to both the difference in the lidars' measuring volumes (Alizé has a larger probe volume but measures over a smaller horizontal measuring area than WLS66) and the flow inhomogeneity near the cliff.

A similar comparison is illustrated in Figure $8 \mathrm{~b}$ panel between 3E and Bura at $150 \mathrm{~m} \mathrm{ASL}$, which are located in pos. 4 and 5 and separated $\approx 550 \mathrm{~m}$, where the wind speeds are also in good agreement ( $1 \%$ bias and $\left.R^{2}=0.99\right)$.

\subsubsection{VAD and Dual Setup}

For this comparison, we merge the dual-setup reconstructed wind speed data with a $100 \%$ actual availability in the chosen range gate with the filtered data described in the previous section, which results in 288610 min means. We choose Bura because it is the VAD lidar furthest inland (pos. 5) and so the dual-setup reconstructed wind speed is more accurate due to the angle between Koshava, Sterenn, and the scanned point. However, Bura is not at the northward position of the lines scanned by the dual setup and so we are comparing two rather different flows. 


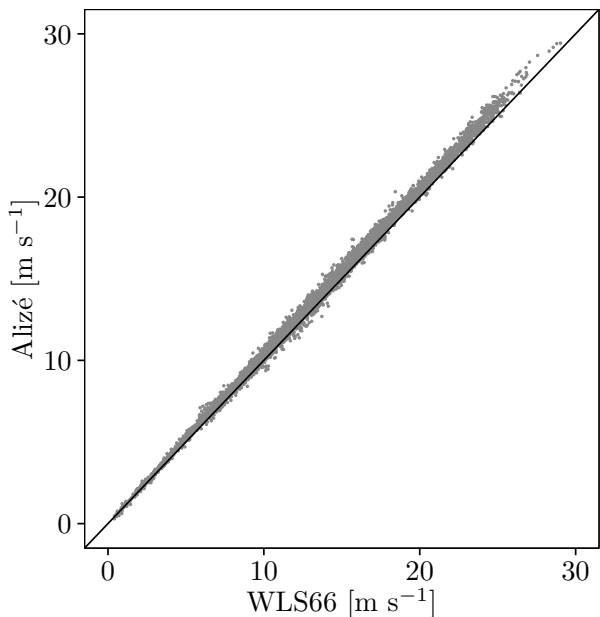

(a)

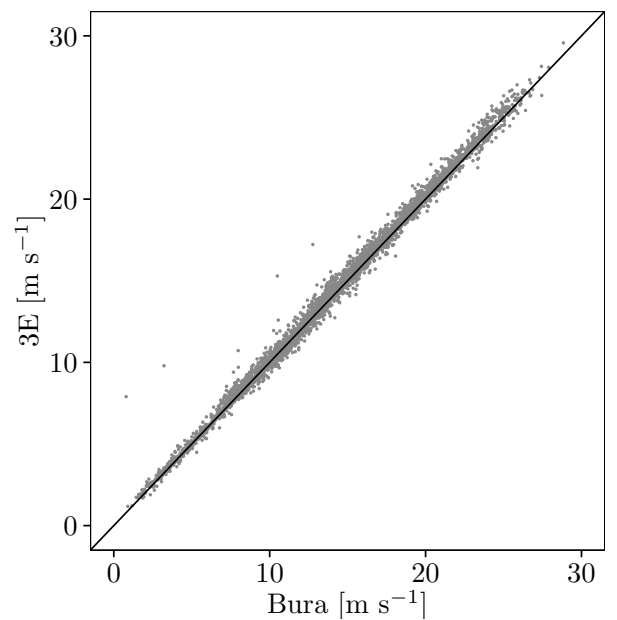

(b)

Figure 8. Scatter plots of $10 \mathrm{~min}$ mean wind speeds at $\approx 126 \mathrm{~m}$ ASL for WLS66 and Alizé (a) and at $150 \mathrm{~m}$ ASL for Bura and 3E (b). A line through the origin with a slope of 1 is shown in black.

Figure 9 shows the scatter plot for a height of $100 \mathrm{~m}$ ASL. Slightly more scatter can be seen compared to those in Figure $8\left(6 \%\right.$ bias and $\left.R^{2}=0.98\right)$. This is also partly due to the effect of having only four samples in the dual setup, whereas Bura samples every $4 \mathrm{~s}$ within the 10 min intervals.

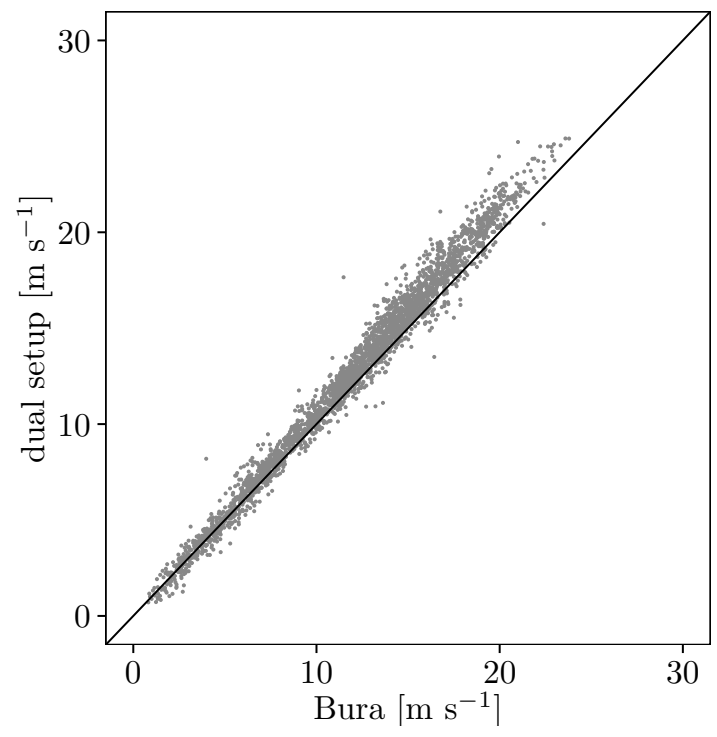

Figure 9. Scatter plot of the 10 min mean wind speeds for Bura and those reconstructed by the dual setup (for the position $x=447,052 \mathrm{~m}$ ) at $\approx 100 \mathrm{~m}$ ASL. A line through the origin with a slope of 1 is shown in black.

\subsubsection{Dual Setup and PPIs}

There are only a limited amount of positions where the scanning patterns from the concurrent dual and PPI setups intersect, and we expect differences in the estimated $10 \mathrm{~min}$ wind speed because of the difference in the size of the measuring volume, and the inherent spatial and temporal variability of the wind speed. The scanning pattern of both setups was chosen such that at $5 \mathrm{~km}$ west of position 2 , and they both measure at 50,100 and $150 \mathrm{~m}$ ASL. Furthermore, there are intersecting points at $50 \mathrm{~m}$ $\mathrm{ASL}, \approx 0.9$ and $1.7 \mathrm{~km}$ west of position 2 . 
Figure 10 shows scatter plots of the 10 min reconstructed mean wind speeds from the PPI and dual setup scans during phases 2 and 3. We only use data with $50 \%$ or higher actual availability within a $10 \mathrm{~min}$ interval to increase the number of $10 \mathrm{~min}$ intervals that can be compared. The number of matching $10 \mathrm{~min}$ intervals is 4964, 4605, 1325, 1218, 1204 for Figure 10 panels a-e, respectively. Panels a and b show the wind speed at $50 \mathrm{~m}$ ASL at $\approx 900$ and $1700 \mathrm{~m}$ west of position 2 , respectively. The agreement is good ( $R^{2}=0.97$ for both panels) but a cluster of points where the PPI scan shows higher wind speeds is clearly seen. The mean bias is $0.1 \%$ and $0.8 \%$ for panels a and $b$, respectively.
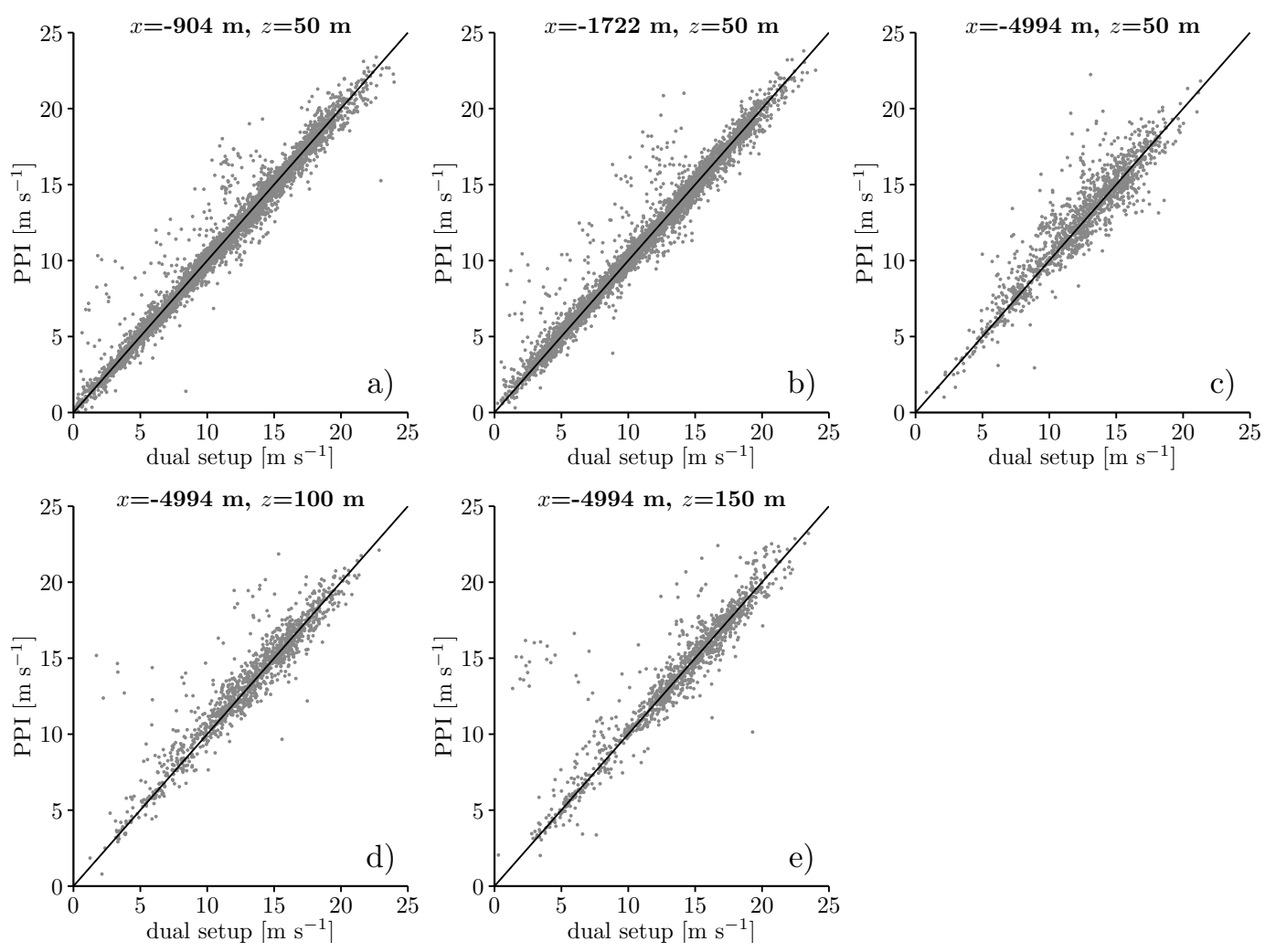

Figure 10. Scatter plots of the $10 \mathrm{~min}$ mean wind speeds for the PPI and dual setups (see text for details). A line through the origin with a slope of 1 is shown in black. The $x$-position is relative to position 2 of Vara with positive values going eastward and the $z$-position is ASL. Scatter plots at positions of $\approx 900$, 1700 and $5000 \mathrm{~m}$ west of position 2 of Vara are shown in panel $(\mathbf{a}, \mathbf{b})$ and $(\mathbf{c}-\mathbf{e})$, respectively.

Figure 10 (panels c-e) shows comparisons at position 7 at 50, 100 and $150 \mathrm{~m}$ ASL. The agreement is also good ( $R^{2}=0.86,0.88$, and 0.83 for 50,100 , and $150 \mathrm{~m} \mathrm{ASL}$, respectively) and the mean bias is $2 \%$ for all heights. The lower agreement found compared to that of the positions closer to position 2 (in panels $\mathrm{a}$ and $\mathrm{b}$ ) are most probably related to the assumption of flow homogeneity within the PPI scan that is needed for wind reconstruction, which is less valid when the PPI scan covers a larger area. At further distances, there will be larger differences between the LOS velocities in a scan, due to the higher spatial separation. This makes it more difficult to reconstruct the wind speed. Furthermore, there can also be a bias due to a physical mean wind speed gradient present in the scanning area.

The wind reconstruction from these PPI scans is less accurate for southerly and northerly winds as the LOS velocities are low and change less within the scan. Figure 11 shows the mean and standard deviation of the difference between the reconstructed wind speed from the dual and the PPI setups at $50 \mathrm{~m} \mathrm{ASL}$ as a function of wind direction. The wind direction was determined from WLS66 at $76 \mathrm{~m}$ AGL due to its high actual availability and sorted into $30^{\circ}$ bins. 


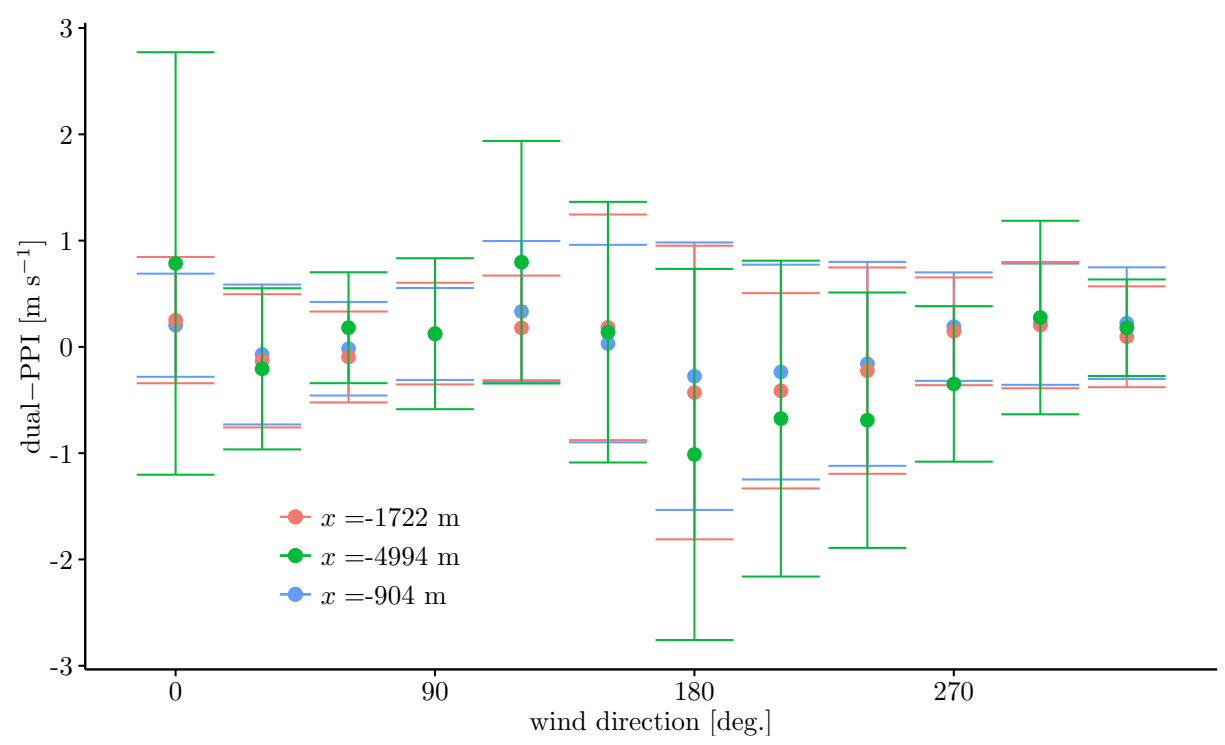

Figure 11. The mean (marker) \pm standard deviation (error bars) of the difference between 10 min mean reconstructed wind speeds from the dual and PPI setups at $50 \mathrm{~m}$ ASL at three different westward positions. The $x$-position is relative to Vara (pos. 2) with positive values going eastward.

From here on, we assume that there is no bias in the dual setup because it needs fewer assumptions for reconstructing the wind speed. For the positions closest to the coast $(x=-904$ and $x=-1722 \mathrm{~m})$, the bias and standard deviation are highest for southerly winds (a mean bias of $\approx 0.3 \mathrm{~m} \cdot \mathrm{s}^{-1}$ for the $180^{\circ}$ sector). For the point near position 7 , there is a bias in mean wind speed for the southerly and southwesterly winds of more than $1 \mathrm{~m} \cdot \mathrm{s}^{-1}$. Very few samples are available for northerly winds, but a clear bias is observed for the furthest westward position. Furthermore, the standard deviation in all direction bins is larger at $x=-4994 \mathrm{~m}$ than at $x=-904 \mathrm{~m}$, which indicates that the reconstructed wind speeds show larger differences between the PPI and the dual-setup scans at large distances.

\section{Conclusions}

The RUNE campaign provides detailed novel measurements of the flow in the coastal zone. The flow during the campaign was mostly westerly, with higher wind speeds than usual in this time of the year and the occurrence of several storms. The availability of four land-based VAD lidars was the highest, generally above 95\%. The PPI and dual setups showed a lower availability for longer ranges due to the decrease in backscatter signal. The virtual mast scenario had the lowest availability of the scanning setups because the wind speed is reconstructed $5 \mathrm{~km}$ from the coast. The power supply of the lidar buoy was damaged by waves several times and experienced long periods of unavailability.

We intercompared the reconstructed $10 \mathrm{~min}$ wind speeds from the lidar LOS velocities. The measurements from two collocated VAD lidars show the highest agreement. Those from two VAD lidars that were separated $\approx 550 \mathrm{~m}$ showed slightly more scatter. The measurements from the dual setup compared well with those from a VAD lidar, despite the largely different sampling rates, measurement volumes, and scanned atmosphere. The $10 \mathrm{~min}$ mean wind speeds from the PPI scan showed good agreement compared with those from the dual setup near the coast and the bias was higher for a sampling location further offshore. Higher uncertainty in the wind speed reconstruction of the PPI scans for situations with low LOS velocities is expected and seen for northerly and southerly winds.

This preliminary analysis shows us the capabilities of the lidar measuring systems of RUNE. However, RUNE's main scientific questions still remain to be answered and the next steps in our analysis will address them. First, we need to find out what is the accuracy of flow models near the coast. This can be performed by evaluating mesoscale and microscale model outputs (and the 
combination of both) against RUNE measurements that also include the satellite and ocean buoy observations. We propose to construct blind benchmark cases based on RUNE's measurements and distribute the description of the cases among the interested audiences. One of those works within the framework of the New European Wind Atlas (NEWA) project [25], in which the RUNE experiment plays an important role. Within NEWA, a number of modelers are going to evaluate the model results, which will be used to obtain the wind atlas, against high-quality measurements. Second, we need to determine which is the best way to perform near-shore wind measurements in terms of accuracy, and economical and logistical feasibility. The dual setup and the PPI scans are the two options that can cover the area of interest; the dual setup needs two relatively expensive scanning lidars but the accuracy of reconstructed wind speeds is high because we do not need to assume horizontal flow homogeneity within the scanned area. The PPI scans can be performed by one scanning lidar, thus reducing costs and logistics, but we need to assume horizontal flow homogeneity within the scanned area, thus increasing the uncertainty. The question is whether the increase in uncertainty has a large impact when performing wind resource predictions and wind-power estimations.

Acknowledgments: Funding from the ForskEL program to the project 'RUNE' No. 12263 and The European Commission partly funded 'New European Wind Atlas' project through FP7 are acknowledged. We would also like to acknowledge 3E for adding the 3E lidar to RUNE's network, Fraunhofer IWES for the measurements from the lidar buoy, and the technicians of DTU Wind Energy, Fraunhofer IWES and the Danish Hydrological Institute for their work and support during the campaign.

Author Contributions: M.C., G.L., A.P. and N.V. conceived and designed the experiments; G.L., N.V. and E.S. performed the experiments; R.F. analyzed the data; R.F. and A.P. wrote the paper.

Conflicts of Interest: The authors declare no conflict of interest.

\section{References}

1. Floors, R.; Vincent, C.L.; Gryning, S.E.; Peña, A.; Batchvarova, E. The wind profile in the coastal boundary layer: Wind lidar measurements and numerical modelling. Bound.-Layer Meteorol. 2013, 147, 469-491.

2. Peña, A.; Gryning, S.E.; Hahmann, A. Observations of the atmospheric boundary layer height under marine upstream flow conditions at a coastal site. J. Geophys. Res. Atmos. 2013, 118, 1924-1940.

3. Mortensen, N.G.; Heathfield, D.N.; Myllerup, L.; Landberg, L.; Rathmann, O. Getting Started with WAsP 9; Technical Report Risø-I-2571(EN); Risø National Laboratory: Roskilde, Denmark, 2007.

4. Frank, H.P.; Rathmann, O.; Mortensen, N.G.; Landberg, L. The Numerical Wind Atlas-The KAMM/WAsP Method; Technical Report Risø-R-1252(EN); Risø National Laboratory: Roskilde, Denmark, 2001.

5. Landberg, L.; Myllerup, L.; Rathmann, O.; Petersen, E.L.; Jørgensen, B.H.; Badger, J.; Mortensen, N.G. Wind resource estimation-An overview. Wind Energy 2003, 6, 261-271.

6. Nunalee, C.G.; Basu, S. Mesoscale modeling of coastal low-level jets: Implications for offshore wind resource estimation. Wind Energy 2014, 17, 1199-1216.

7. Badger, J.; Frank, H.; Hahmann, A.N.; Giebel, G. Wind-climate estimation based on mesoscale and microscale modeling: Statistical-dynamical downscaling for wind energy applications. J. Appl. Meteorol. Climatol. 2014, 53, 1901-1919.

8. Smith, D.A.; Harris, M.; Coffey, A.S.; Mikkelsen, T.; Jørgensen, H.E.; Mann, J.; Danielian, R. Wind lidar evaluation at the Danish wind test site in Høvsøre. Wind Energy 2006, 9, 87-93.

9. Gottschall, J.; Courtney, M.S.; Wagner, R.; Jørgensen, H.E.; Antoniou, I. Lidar profilers in the context of wind energy - A verification procedure for traceable measurements. Wind Energy 2012, 15, 147-159,

10. Pauscher, L.; Vasiljevic, N.; Callies, D.; Lea, G.; Mann, J.; Klaas, T.; Hieronimus, J.; Gottschall, J.; Schwesig, A.; Kühn, M.; et al. An Inter-Comparison Study of Multi- and DBS Lidar Measurements in Complex Terrain. Remote Sens. 2016, 8, 782.

11. Vasiljević, N. A Time-Space Synchronization of Coherent Doppler Scanning Lidars for 3D Measurements of Wind Fields. Ph.D. Thesis, Danish Technical University, Roskilde, Denmark, 2014.

12. Vasiljević, N.; Lea, G.; Courtney, M.; Cariou, J.P.; Mann, J.; Mikkelsen, T. Long-Range WindScanner System. Manuscript in Prep. Available online: http://dx.doi.org/10.20944/preprints201610.0017.v1 (accessed on 13 October 2016). 
13. Berg, J.; Vasiljevic, N.; Kelly, M.; Lea, G.; Courtney, M. Addressing spatial variability of surface-layer wind with long-range WindScanners. J. Atmos. Ocean. Technol. 2015, 32, 518-527.

14. Floors, R.; Lea, G.; Peña, A.; Karagali, I.; Ahsbahs, T. Report on RUNE's Coastal Experiment and First Inter-Comparisons between Measurements Systems; Technical Report E-0115(EN); DTU Wind Energy: Roskilde, Denmark, 2016.

15. Peña, A.; Floors, R.; Sathe, A.; Gryning, S.E.; Wagner, R.; Courtney, M.S.; Larsén, X.G.; Hahmann, A.N.; Hasager, C.B. Ten years of boundary-Layer and wind-power meteorology at Høvsøre, Denmark. Bound.-Layer Meteorol. 2016, 158, 1-26.

16. Courtney, M.; Simon, E. Deploying Scanning Lidars at Coastal Sites; Technical Report E-0110(EN); DTU Wind Energy: Roskilde, Denmark, 2016.

17. Geostyrelsen. Available online: http://download.kortforsyningen.dk/content/dhm-2007overflade-16-mgrid (accessed on 21 June 2016).

18. European Environment Agency. Available online: http://www.eea.europa.eu/data-and-maps/data/corineland-cover-2006-raster-3\{\#\}tab-metadata (accessed on 21 June 2016).

19. Pindea, N.; Jorba, O.; Jorge, J.; Baldasano, J.M. Using NOAA-AVHRR and SPOT-VGT data to estimate surface parameters: Application to a mesoscale meteorological model. Int. J. Remote Sens. 2004, 25, 129-143.

20. Troen, I.; Petersen, E.L. European Wind Atlas; Risø National Laboratory: Roskilde, Denmark, 1989; p. 656.

21. Floors, R.; Gryning, S.E.; Peña, A.; Batchvarova, E. Analysis of diabatic flow modification in the internal boundary layer. Meteorol. Z. 2011, 20, 649-659.

22. Liang, X. An integrating velocity-Azimuth process single-Doppler radar wind retrieval method. J. Atmos. Ocean. Technol. 2007, 24, 658-665.

23. Simon, E.I.; Courtney, M.S. A Comparison of Sector-Scan and Dual Doppler Wind Measurements at Høvsøre Test Station-One Lidar or Two? Technical Report DTU Wind Energy E-0112(EN); DTU Wind Energy: Roskilde, Denmark, 2016.

24. Gottschall, J.; Wolken-Möhlmann, G.; Viergutz, T.; Lange, B. Results and conclusions of a floating-lidar offshore test. Energy Procedia 2014, 53, 156-161.

25. Mann, J.; Angelou, N.; Arnqvist, J.; Callies, D.; Cantero, E.; Chávez Arroyo, R.; Courtney, M.; Cuxart, J.; Dellwik, E.; Gottschall, J.; et al. Complex terrain experiments in the New European Wind Atlas. Philos. Trans. R. Soc. A 2016, in press.

(C) 2016 by the authors; licensee MDPI, Basel, Switzerland. This article is an open access article distributed under the terms and conditions of the Creative Commons Attribution (CC-BY) license (http://creativecommons.org/licenses/by/4.0/). 